\title{
Twelve year experience of laparoscopic gastric plication in morbid obesity: development of the technique and patient outcomes
}

\author{
Mohammad Talebpour ${ }^{1}$, Seyed Mohammad Kalantar Motamedi ${ }^{1,2}$, Atieh Talebpour ${ }^{1}$ and Hamed Vahidi ${ }^{1,2^{*}}$
}

\begin{abstract}
Background: Laparoscopic Gastric Plication (LGP) is a new restrictive bariatric surgery, previously introduced by the author. The aim of this study is to explain the modifications and to present the 12-year experience, regarding early and long term results, complications and cost.

Methods: We used LGP for morbid obesity during the past 12 years. Anterior plication (10 cases), one-row bilateral plication while right gastroepiploic artery included (42 cases), and excluded from the plication (104 cases) and two-row plication (644 cases). The gastric greater curvature was plicated using 2/0 prolen from fundus at the level of diaphragm preserving the His angle to just proximal to the pylorus. The anatomic and functional volume of stomach was $50 \mathrm{cc}$ and $25 \mathrm{cc}$ respectively in two-row method. Ordered postop visits also included evaluation of weight loss, complications, change of diet and control of exercise.

Results: LGP was performed in 800 cases (mean age: 27.5, range: 12 to 65 years, nine under 18). Female to male ratio was $81 \%$ to $19 \%$ and average BMI was 42.1 (35-59). The mean excess weight loss (EWL) was $70 \%$ (40\% to $100 \%)$ after 24 months and 55\% (28\% to 100\%) after 5 years following surgery. 134 cases (16.7\%) did not completed long term follow-up. The average time of follow up was 5 years ( 1 month to 12 years). 5.5\% and 31\% of cases complained from weight regain respectively during 4 and 12 years after LGP. The mean time of operation was 72 (49-152) minutes and average hospitalization time was 72 hours (24 hours to 45 days). The cost of operation was 2000 \$ less than gastric banding or sleeve and 2500 \$ less than gastric bypass. Eight patients out of 800 cases (1\%) required reoperation due to complications like: micro perforation, obstruction and vomiting following adhesion of His angle. Other complications included hepatitis pneumonia, self-limiting intra-abdominal bleeding and hypocalcaemia.
\end{abstract}

Conclusion: The percentage of EWL in this technique is comparable to other restrictive methods. The technique is safe with $1.6 \%$ complication ( $1 \%$ reoperated), and $31 \%$ regain during 12 years. The cost of operation is less than the other methods.

Keywords: Morbid obesity, Laparoscopy, Gastric plication, Restriction

\footnotetext{
* Correspondence: hamedv2@gmail.com

'Laparoscopic Surgical Ward, Sina Hospital, Tehran University of Medical Sciences, Tehran, Iran

${ }^{2}$ Endocrinology and Metabolism Research Center, Tehran University of Medical Sciences, Tehran, Iran
} 


\section{Background}

Modern life has influenced on amount of physical activity and form of diet [1-4]. As a result there is an increasing trend in prevalence of morbid obesity around the world [5-8]. Although there are few cases with congenital, genetic or hormonal etiology of morbid obesity, the main factor is habitual. Change of lifestyle including more exercise and a low fat and calorie diet is the fundamental plan for morbid obese patients treatment [9].

Influence of diet and exercise in morbid obese patients is about $10 \%$ in long term period; thus, in case of lifestyle modification failure, bariatric surgery could be considered [10]. They need a potential trigger for weight loss like restrictive bariatric surgeries that are effective to preserve diet for about 4 years $[11,12]$. Other methods have limited and temporary effect. Such methods are not recommended choices in long term i.e. drugs and hypnosis etc. [13].

Restrictive methods (RM) are the most conservative bariatric surgery especially for newly risen type of morbid obese patients as they are more knowledgeable nowadays. This group mainly contains patients with history of high calorie intake and low activity during adolescence. But patient has a new insight to lose weight due to maturity of mind and finding problems of obesity after puberty.

The mean EWL in different forms of restrictive methods is almost the same [14-17]. Efficacy of RM is not mainly related to the type of technique. Although adequate weight loss always occurs, patient's cooperation is the key factor for its effectiveness. Long term results showed that weight regain only occurs in a few cases due to temporary effect of restrictive methods and discontinuing diet and exercise [18,19]. Malabsorptive method has longer effect on weight loss but the risk of late complications due to vitamin deficiency and anemia is noticeable [20].

As the number of these patients is increasing, and also different restrictive methods cause relatively considerable rate of early complications [21-25], author designed a new restrictive method after different stages of animal study named as Laparoscopic Gastric Plication (LGP) 12 years ago $[26,27]$. The main aim of this paper is to present the 12 year experience on more than 800 cases of LGP and their long term outcome data. As this technique has been improved as a result of study on Iranian cases, and it has gained currently widespread

Table 1 Indication of bariatric surgery

\begin{tabular}{ccc}
\hline METHOD/LANDMARK & MOTIVATION & SAMPLE \\
\hline LGP & EXCELLENT & YOUNG FEMALE \\
GBP & MODERATE & MALE DIABETIC \\
DS & POOR & SUPER OBESE \\
\hline
\end{tabular}

LGP: Laparoscopic gastric plication, GBP: Gastric bypass, DS: Duodenal switch. usage in the world, the author chose the Iranian Method title on the honor of these patients.

\section{Methods}

This prospective case series study has been mainly performed in Laleh and Sina Hospitals, Tehran, Iran by the first author since 12 years ago.

\section{Patients}

After some years of experience, based on wide range of EWL results and assessment of individuals, the key factor for case selection was related to one's motivation and cooperation. Gastric plication was selected for cases with potential for continuous diet and exercise after operation. They are mostly young single females with the history of obesity during adolescence and hate of obesity at the time of operation. In cases with moderate rate of motivation the preferred method was mixed technique (gastric bypass). They were mainly males, diabetic cases, and middle aged females. The third group with poor motivation and predominantly psychological problems was candidate for malabsorptive technique without any restrictive option (Table 1).

Any patient with BMI over 40 or 35 with comorbidity was selected for LGP. During the first 6 years of experience only patients with age of more than 18 years were selected. But afterwards when LGP method was modified, this was also applied for some selected well oriented adolescent patients. LGP performed for adolescents after psychological consult and achieving good motivation.

If this operation made acceptable excess weight loss (EWL) even in super obese cases, there was no need for second stage operation. But in weight regain cases (who had appropriate primary progress in weight loss during first year but their trend reversed into weight gain afterwards; so that their current cumulative weight loss is less that $30 \%$ of primary excess weight) or patients with unacceptable EWL (less than 30\% after 6 months), the

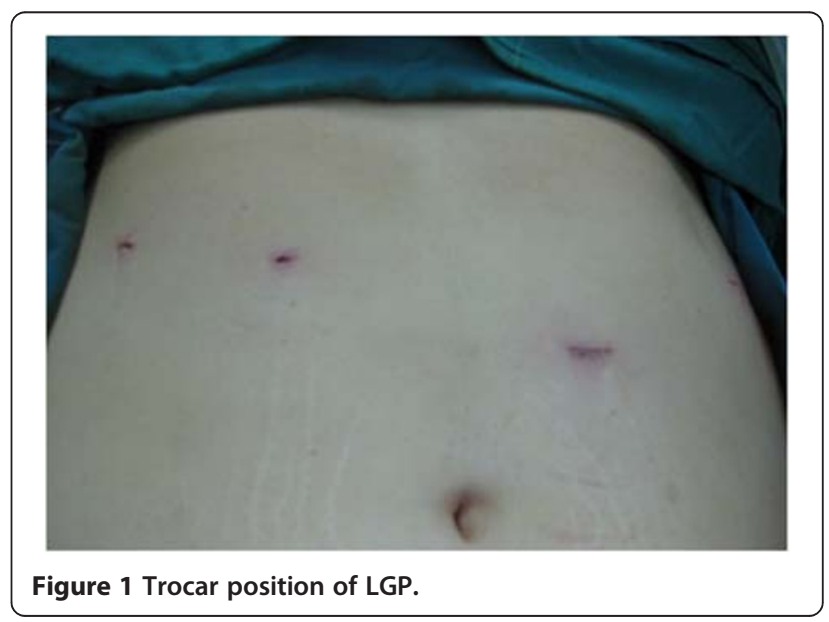



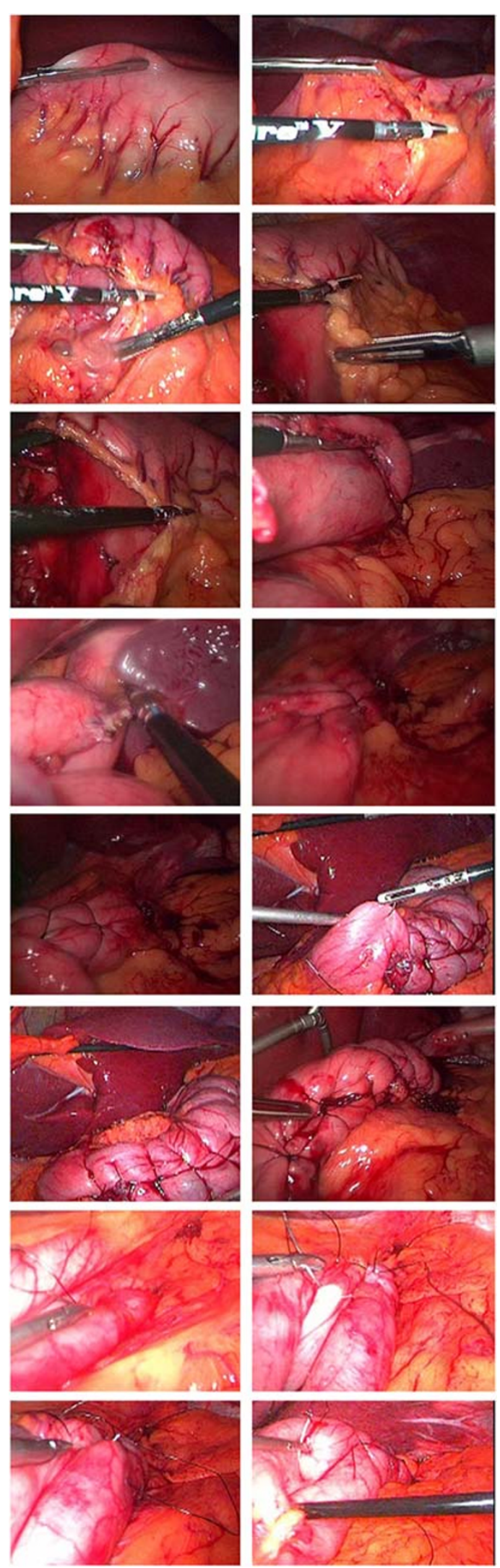

Figure 2 Different steps of LGP.

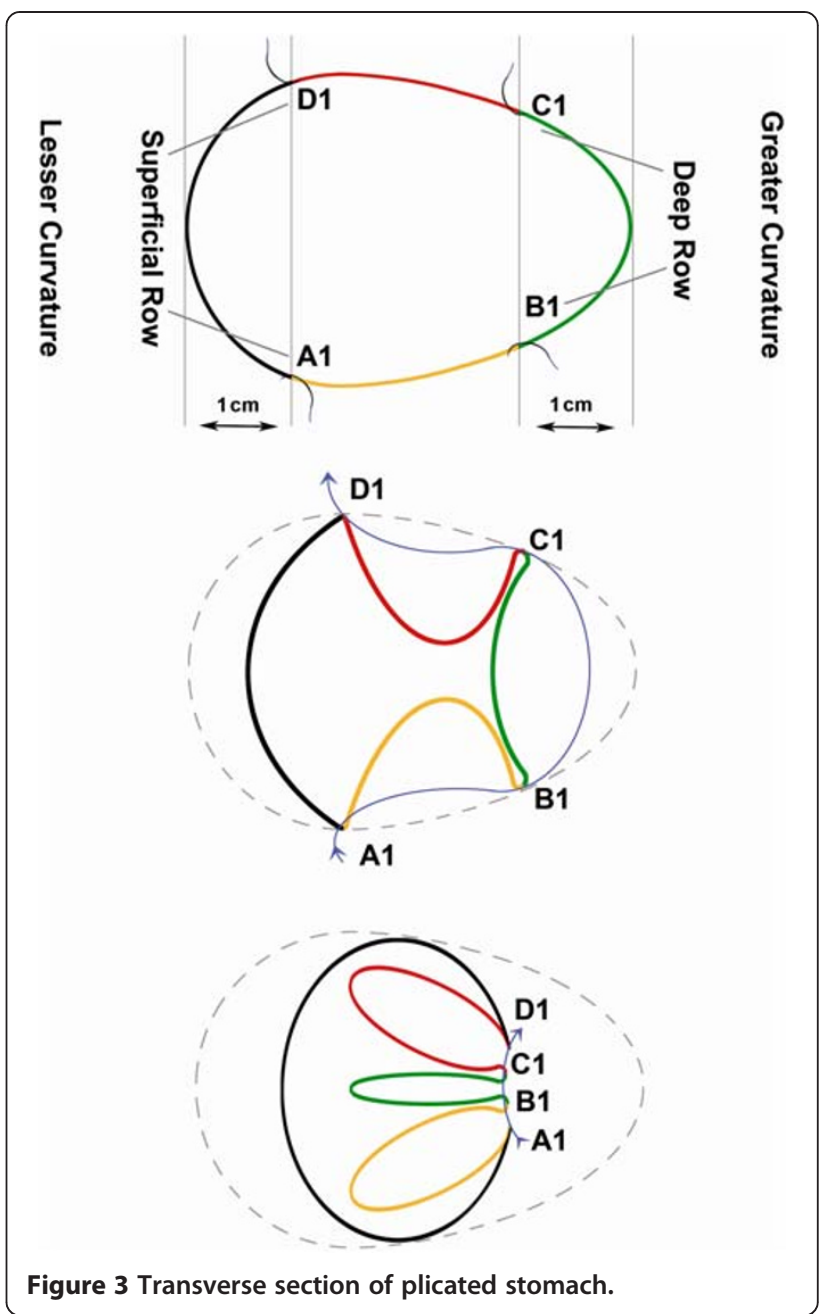

second stage operation was advised after 4 years in regain and 6 months in failure cases. At this stage without any change in the first part, laparoscopic malabsorptive method was performed. In patients who had complained about GERD as a comorbidity of morbid obesity, the plan of operation was funduplication of Nissen and plication of the remaining of stomach. If hiatal hernia was seen during operation closure of crus was enough.

Characteristic data was taken using standard questionnaire and patients were interviewed to evaluate their psychological issues and motivation. Anthropometric measures were recorded and informing consent was taken. Preop work ups included sonography of gallbladder, hormonal, electrolytes, liver function and blood coagulation tests.

\section{Setup}

Lower limb bandage, prophylactic heparin, pantazol and antibiotic therapy were advised in all cases. Position of patients was supine with 30-degree reverse trendelenburg. 


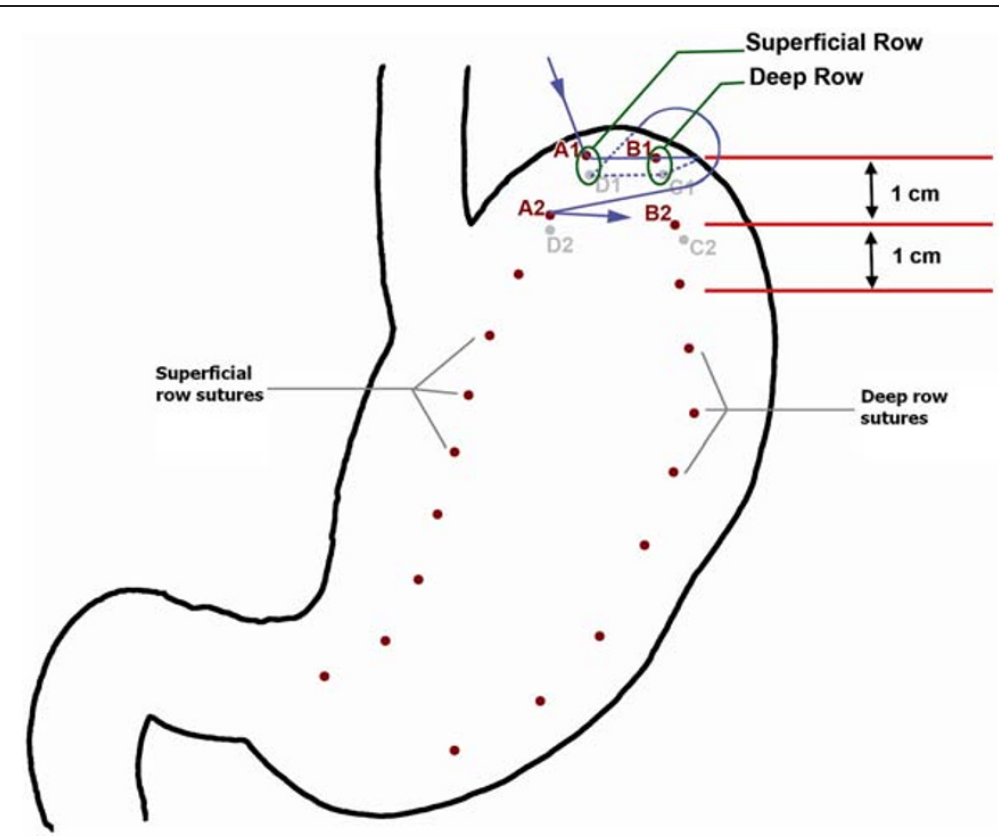

Figure 4 Anterior view before plication with marked points of each bite.

Pneumoperitoneum performed by $\mathrm{CO} 2$ with $12-15 \mathrm{mmHg}$ pressure via left subcostal insertion of Verress needle at mid-axillary line. The first trocar placed at left paramedian line $20 \mathrm{~cm}$ away from xyphoid angle (telescope trocar). Left and right hands of surgeon's trocars were inserted based on ergonomic assessment at this stage (left middle axillary line at subcostal (insertion site of Verress needle) and right mid-clavicular line at $5 \mathrm{~cm}$ above the first trocar). The second surgeon's trocar was inserted at right anterior axillary line. Almost always one $10 \mathrm{~mm}$ and three $5 \mathrm{~mm}$ trocars used (Figure 1).

\section{Dissection}

Anterior wall of stomach at prepyloric area grasped and pulled up at first step. Dissection was started in contact to gastric wall releasing the greater curvature from prepyloric area up to almost $2 \mathrm{~cm}$ to His angle, (just after separation of stomach from spleen in contact to

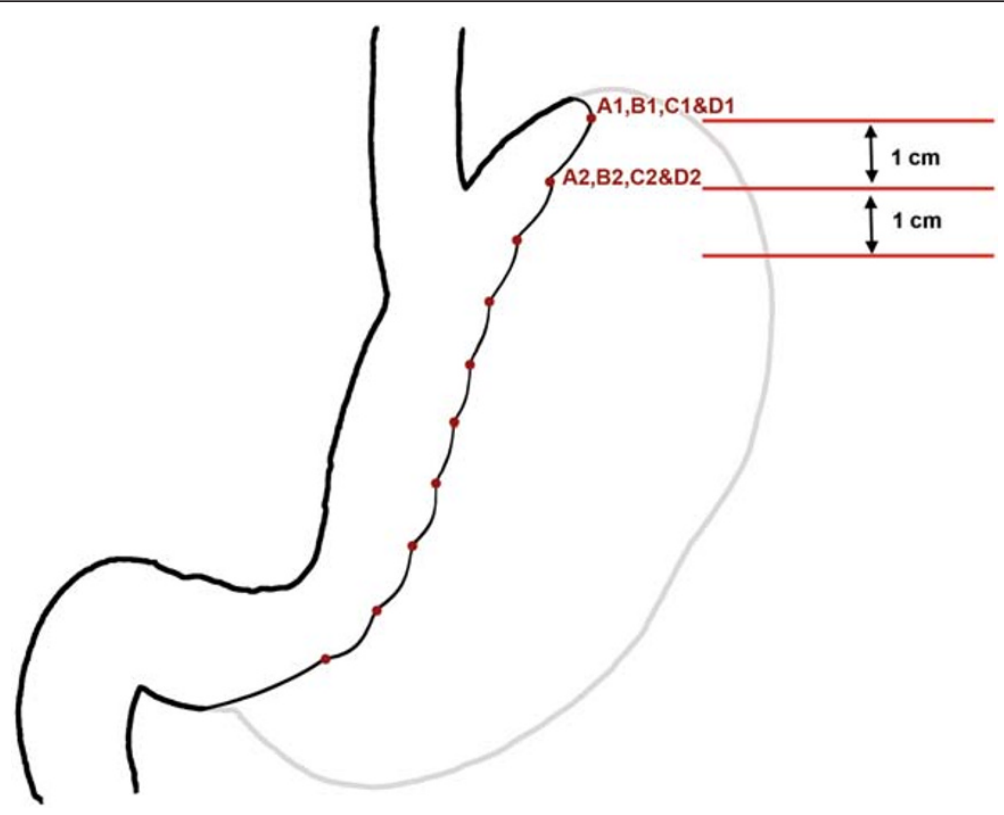

Figure 5 Anterior view after plication preserving His Angle. 
diaphragm) preserving the anatomy of His angle and sacrificing left and right gastroepiploic artery. All greater curvature vessels were ligated by intra corporeal suturing, clips or coagulation at earlier times (2000 to 2004) and by LigaSure ${ }^{\mathrm{TM}}$ or Ultracision later on.

\section{Plication}

The aim of procedure was restriction of or ideally packing as much space of stomach as possible via folds (plications) from its own wall. During first 6 years of experience, one-row plication was performed, followed by 6 years of two-row plication (Figure 2). It was done by invagination of three sections of gastric wall from the perimeter of greater curvature. As illustrated schematically in Figure 3, in order to have three sections (AB, BC and $C D$ ), it was obviously needed to have four separation points of A, B, C and D (which represent the locations of suture bites). There would be four bites at each transverse level; two (A and B) in anterior and two $(\mathrm{C}$ and $\mathrm{D})$ in posterior gastric wall. These points were repeated at many levels $(1,2,3 \ldots, \mathrm{n})$ from top at the fundus to bottom at prepyloric area of stomach. At each level, bites $\mathrm{A}$ and $\mathrm{D}$ were about $1 \mathrm{~cm}$ (but increasing proportional to the diameter of respective stomach section) away from right aspect of the stomach and B and $\mathrm{C}$ were about $1 \mathrm{~cm}$ away from the greater curvature. Points A and D in all levels together comprise outer or superficial suture row while Bs and Cs make the deep or inner suture row (Figure 4). These two rows would not be practically separate at the end because pulling the thread passed across the four points will approximate all the points together at the left side of stomach (Figure 5). The thread was never to be cut during the procedure and all the bites were continuous. For the first level of bites, bite one (A1) was inserted almost $2 \mathrm{~cm}$ above His angle below the attaching part of fundus to the diaphragm. Next bite (B1) was taken at anterior and near the greater curvature; then the posterior ones $\mathrm{C} 1$ and D1 were taken from posterior wall respectively mirror to B1 and A1 bites. Pulling the thread resulted in inward plication of greater curvature composed of three folds of $\mathrm{AB}, \mathrm{BC}$ and $\mathrm{CD}$. The three folds were almost the same size and had almost $2 \mathrm{~cm}$ bulk of gastric wall. Next level was $1 \mathrm{~cm}$ below the first one and suturing order was started again from A1 not D1. Continuing this procedure, level by level, ended in plication of three longitudinal folds of gastric wall into stomach. 00 prolen or nylon was used. Sutures were seromuscular, so that it was far away gastric acid. To assure the best site for suture intraluminal guide (No. 36) was used primarily. The gastric volume was calculated in passive state in operating room at the end of operation in first ten cases. The anatomic volume was measured by transient occlusion of pylorus by an atraumatic grasper and infusion of liquid to stomach freely and without any forced pressure (so that it was equal to atmosphere pressure) using red nasogastric tube (NGT) until we can see the level of liquid at the mouth. The calculated volume minus the volume of retained liquid in the esophageal part of NGT was taken as the real volume of stomach.

\section{Postop}

In the very first cases (about 10) postoperative endoscopy was performed to find out position of inverted fold. But no guide or endoscopy was applied routinely later on.

Intravascular infusion of liquid (4-5 liters of dextrose half saline daily) was advised after operation to decrease the risk of DVT and increase the potential of mobilization. Patients did not have Foley catheter or NGT after operation and they were mobilized after about 4 hours of operation. ICU admission was not routinely advised. Patients were discharged after 24 hours of operation in the first 100 cases but the plan changed to 3 days observation with high amount of IV infusion due to very low intake of water. The average time of follow up was 5 years ( 1 month to 12 years).

During first 6 postoperative weeks no solid food which was soft-liquid (2Weeks), semi-liquid (2Weeks) and semi-solid food (2Weeks) were advised until the patient could be able to eat normal meal (Table 2).

The volume of prescribed liquid intake was 2 liters per day orally or intravascular infusion after hospital discharge. It should be noted that the patients are unable

Table 2 Plan of diet after LGP

\begin{tabular}{|c|c|c|c|}
\hline TIME/DIET & LIQUID & SEMI LIQUID & SOLID \\
\hline HOSPITAL & 4-5 LITERS SERUM THERAPY & - & - \\
\hline 1TH WEEK & 1 LITER (MILK, JUICE, WATER, SYRUP) & - & - \\
\hline 2TH WEEK & 2 LITER(MILK, JUICE, WATER, SYRUP) & - & - \\
\hline $3-4^{\mathrm{TH}}$ WEEKS & 400CC SOUP, 800CC WATER & SLICED FRUIT, YAGURT & - \\
\hline $5-6^{\text {TH }}$ WEEKS & 800CC WATER & 400CC SOUP AND MEAT, YAGURT & FRUIT \\
\hline 1.5-3 MONTHS & 800CC WATER & YAGURT $100 C C$ & BREAD $50 \mathrm{gr}$, CHEESE, MEAT $50 \mathrm{gr}$ \\
\hline 4-6 MONTHS & 800CC WATER & YAGURT 200CC & BREAD $100 \mathrm{gr}$, CHEESE, MEAT $100 \mathrm{gr}$ \\
\hline
\end{tabular}


Table 3 Excess weight loss after LGP

\begin{tabular}{ccccccccccc}
\hline PLICATION & $\mathbf{1}$ MON & $\mathbf{2}$ MON & 3 MON & 6 MON & 1 YEAR & 2 YEAR & 3 YEAR & 4 YEAR & 5 YEAR & 10 YEAR \\
\hline EWL & $20 \%$ & $35 \%$ & $45 \%$ & $60 \%$ & $67 \%$ & $70 \%$ & $66 \%$ & $62 \%$ & $55 \%$ & $42 \%$ \\
PATIENTS & 779 & 745 & 711 & 615 & 491 & 356 & 251 & 176 & 134 & 35 \\
\hline
\end{tabular}

EWL: excessive weight loss.

to take more than 1 liter of liquid in first week due to edema which subsides afterwards.

Supplemental vitamin and especial trace elements were advised. Patients took heparin (prophylactic), pantazol, antibiotics, vitamin C and B complex, apotel, pethidine, metoclopramide and ondansetron during first 2 days. Then milk of Magnesium, syrup of multivitamin and syrup of acetaminophen for the first month used and followed by routine capsules of vitamins.

We also assessed the amount of fluid the subjects were able to take at early postop and at first 6 and 24 months intervals. The measure was based on patient's potential of painless eating. EWL was recorded regularly after surgery.

Control sonography was done to assess the liver condition in one year time. All patients were followed at regular sessions recording weight changes and investigated for any complications. Functional gastric volume and its changes were recorded periodically. Functional gastric volume was defined as maximum amount of intake above which it induces sharp pain or vomiting which was initial preventive mechanism from excessive oral intake.

The rate of gastric volume expansion was compared between one-row and two-row plications. It was also evaluated by endoscopy and contrast study for any unwanted expansion event.

All of patients were on diet and exercise as the order. The main point of their diet was to decrease glucose and fat as much as possible. The prescribed volume of oral intake was dependent to the type of food ingredients. This should be considered because the functional gastric volume was associated with food ingredients such as proteins, carbohydrates or water due to different levels of peristalsis induced to gastric muscle.

\section{Diet}

The diet designed to contain 800 kilo calorie per day in first 6 months after surgery. After 24 hours of operation soft liquids such as milk (100cc), syrup as solution of sugar in water $(200 \mathrm{cc})$, fruit juice $(300 \mathrm{cc})$ and water $(400 \mathrm{cc})$ started with up to $25 \mathrm{cc}$ each 15 minutes during the wakefulness time (1 liter) (first plan). After 1 week of operation the volume of the same soft liquids increased up to $50 \mathrm{cc}$ each time (2 liters daily) for one week (second plan) due to reduction in edema. During the third and fourth weeks syrup was changed to the liquid extract of boiled meat and vegetables, milk changed to soft yogurt and juice to slice fruits (apple, orange) with the same volume (Third plan). The aim of third plan was to stop any sugar intake and start cooked foods supplying mainly proteins and vitamins. Fourth plan of diet was about 2 weeks and included normal yogurt, whole dish of boiled meat and vegetable, normal fruits and 1 liter of water. The strategy of ingesting $50 \mathrm{cc}$ each time was continued for at least 6 months. The fifth and sixth plans of diet were about 1.5 and 3 months and included bread, cooked meat and salad. Exercise in the form of walking for 1 hour each day was the advised plan from the second month of operation. Supplemental therapy began immediately in the form of spray and syrup at first and continued after 1 month by capsules (Table 2).

\section{Results}

In this prospective case series study 800 cases were included. The mean age of patients was 27.5 years old (12-65). Nine patients less than 18 years old (adolescents) also were included in the study whose indication for surgery was high speed of weight gain and risk of super obesity. For adolescents, Excess weight loss (EWL) was generally the same as adults. 9 adolescent patients had 54\% EWL after 6 months and $62 \%$ after 12 months. In all the ratio of female to male was 650 to 150 (81\% to $19 \%)$. Mean BMI of patients was 42.1 (35-59). The mean EWL was $20 \%$ (13\% to $40 \%$ ) after one month (779 cases), 35\% (20\% to 60\%) after 2 months (745 cases), $45 \%$ (25\% to $75 \%)$ after 3 months ( 711 cases), $60 \%$ (28\% to $100 \%$ ) after 6 months (615 cases), $67 \%$ (35\% to $100 \%)$ after 12 months (491 cases), 70\% (40\% to 100\%) after 24 months (356 cases), 66\% (35\% to 100\%) after 3 years (251 cases), 62\% (30\% to 100\%) after 4 years (176 cases)

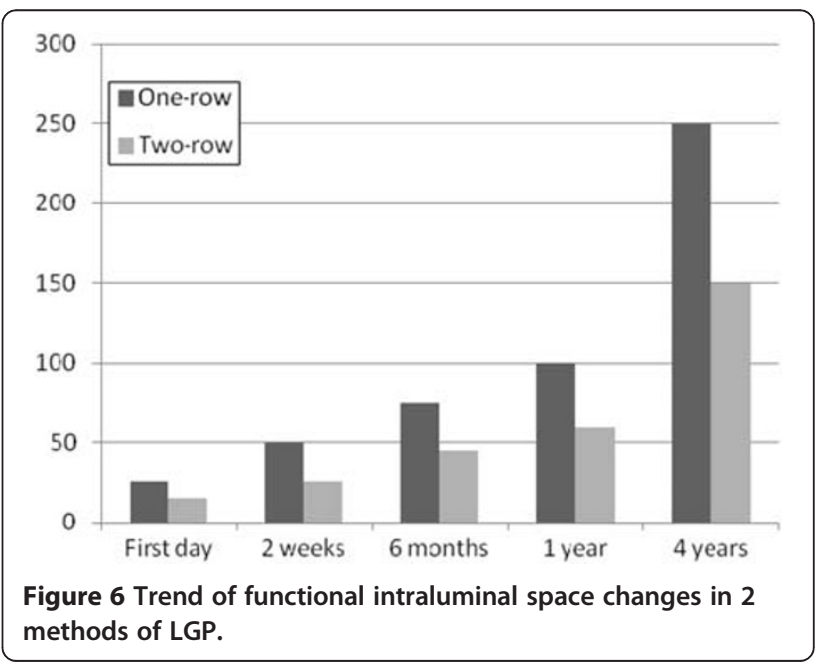



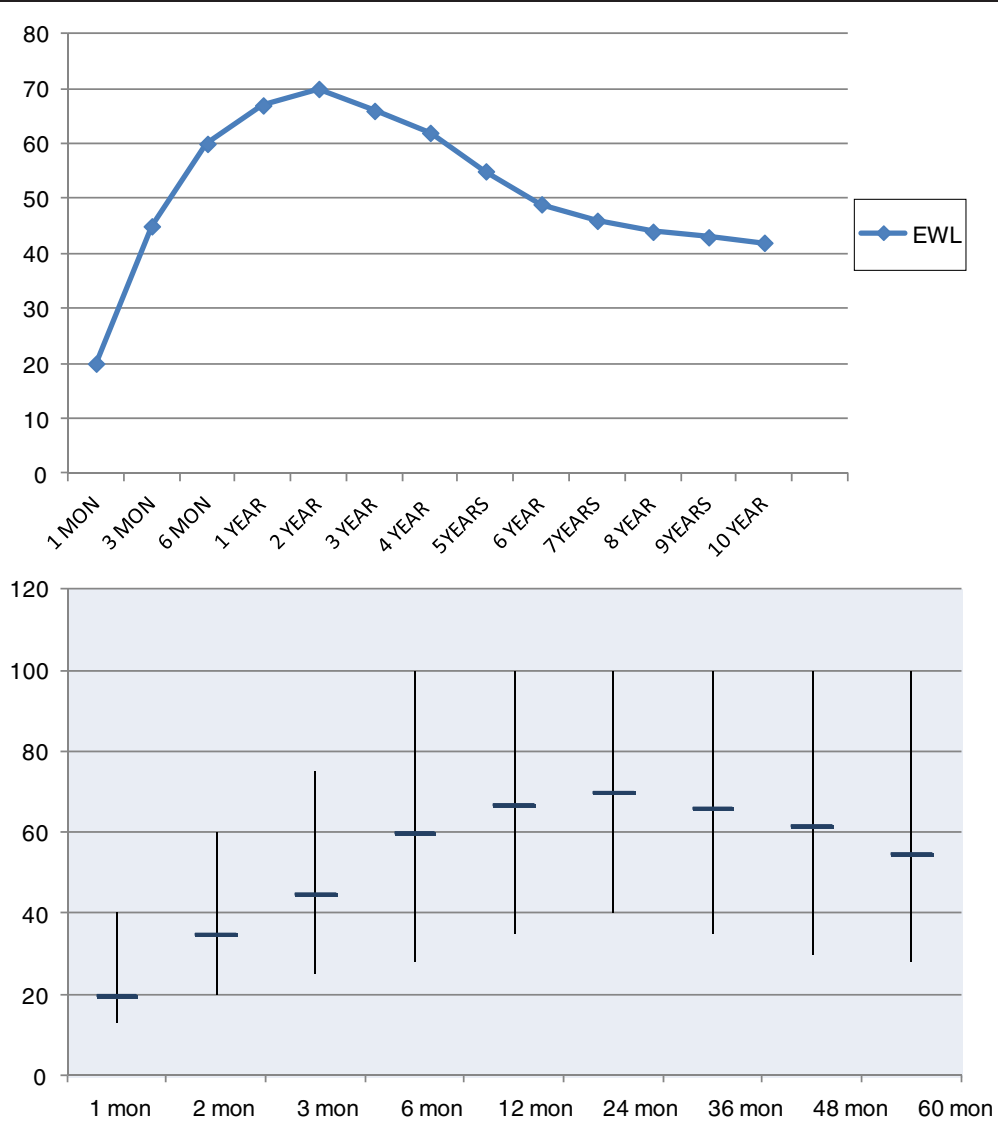

Figure 7 EWL after LGP, A Mean Percentages of EWL from baseline amount during 5 years of follow up; B Mean Percentages of EWL from baseline amount during 5 years of follow up and their variance in cases and its range as vertical lines.

and $55 \%$ (28\% to $100 \%)$ after 5 years (134 cases) following surgery. The average time of follow up was 5 years (one month to 12 years). 134 (16.7\%) cases were lost to follow-up in long term and partially included in EWL results (Table 3 ).

The technique of laparoscopic gastric plication (LGP) was performed in all cases including those with large fatty liver, hiatal hernia and adhesions from previous operation. Sonography showed gallstone in 52 cases (6.5\%) and cholecystectomy was performed at the same time. History of cholecystectomy was positive in 21 cases $(2.6 \%)$.

Fatty liver was reported in $85 \%$ of cases (682 cases) by sonography in different grades including: 421 cases (52\%) grade G1, 154 (19\%) cases G2 and 107 cases (13\%) G3. After one year of LGP report of fatty liver by checkup sonography was as below: 211 out of 242 cases $(87 \%)$ of G1 recovered completely, 45 cases out of 91 (49\%) of G2 recovered completely and 27 (29\%) of them changed into G1,35 out of 102 cases (34\%) of G3 recovered completely and 48 cases down staged (47\%).

The average anatomic volume of stomach in the operating room was 100 and $50 \mathrm{cc}$ in one- and tow-row plication respectively. But The functional volume of stomach in one- and two-row LGP respectively was about 25 and $15 \mathrm{cc}$ at first, 50 and $25 \mathrm{cc}$ after 2 weeks, 75 and 45cc after 6 months, 100 and 60cc after 1 year and 250 and 150cc after 4 years (Figure 6). The functional volume was highly related to the kind of food. If the patient was eating something rich of proteins the amount of functional intake was considerably less compared with the time something with high carbohydrate ingredients was taken. In some especial form of diet such as plain water or sweet water etc. the functional restriction did not happen until the anatomic volume was reached. The appetite of patients decreased after operation due to total gastric volume restriction. They described this feeling as like the condition after eating more than usual with complete fullness of stomach.

Table 4 Postoperative problems after LGP

\begin{tabular}{lc}
\hline POSTOPERATIVE PROBLEM & DETAIL \\
\hline VOMITING & common, mean 2 days postop \\
REFLUX & $2 \%$ after 3 months \\
EPIGASTRIC PAIN & $35 \%$, after 48 hours, \\
\hline
\end{tabular}


Table 5 Postoperative complications after LGP

\begin{tabular}{lccc}
\hline REOPERATION & DETAIL & TECHNICAL INDIPENDENT & DETAIL \\
\hline PERFORATION & 3 CASES & HEPATITIS & HALOTAN INDUCED, 2 CASE \\
OBSTRUCTION & 3 CASES & HYPOCALCEMIA & RARE CASE REPORT \\
PERMANENT VOMITING & 1 CASE & ASPIRATION & 1 CASE \\
INTRACAPSULAR ABSCESS & 1 CASE & BLEEDING & 1 CASE \\
TOTAL & 8 CASES $(1 \%)$ & TOTAL & 5 CASES (0.6\%) \\
\hline
\end{tabular}

The weight loss curve had prominent slope during first 6 months but for next 18 months showed decreased rate (Figure 7).

Mild to moderate weakness during first 3 weeks was common. Vomiting and nausea was seen in all of cases for at least 4 hours and the longest time was 24 days (average time was 2.1 days) which resolved spontaneously. Epigastric pain was seen in 35\% of cases for 48 hours which relieved quickly by antacids. Temporarily during the first Postop week, reflux was seen in $16 \%$ (128 out of 800) of cases without any preop history of reflux symptoms. It changed to less than $2 \%$ after 3 months concurrently with about $45 \%$ EWL.

16 patients out of 615 had problems after 6 months which only one of them required reoperation to undo the plication due to long term vomiting secondary to adhesion of liver to the His angle. Others including 2 patients with gastritis and 13 with persistent reflux were controlled by medical therapy (Table 4).

The price of hospitalization and instruments used in gastric plication was $2000 \$$, while gastric bypass would cost $4500 \$$ and sleeve or banding $4000 \$$ in Laleh Private Hospital [28].

\section{Complications}

The rate of unrelated complications was $0.6 \%$ (5 cases out of 800). In two cases, non-obstructive jaundice appeared for more than 2 weeks after operation which resolved spontaneously. Liver enzymes were very high. The etiology was drug induced hepatitis.

Symptomatic hypocalcemia was seen in one patient secondary to lack of intake. She had hypercalciuria in her past medical history and since she got enough calcium supplements, became asymptomatic. Aspiration pneumonia occurred in one subject who underwent 2 weeks postoperative treatment. Mild bleeding due to anticoagulation therapy was seen in one case which stopped by conservative management and 2 units of fresh blood transfusion. Although dissection of greater curvature was with the risk of bleeding but in our cases blood transfusion was needed only once.

Postoperative technical complications were seen in 8 cases out of $800(1 \%)$. Micro perforation occurred in three cases; the first one occurred at the site of gastric holding by grasper at prepyloric area which was closed by simple suture without any change in plication via laparotomy; one case at the site of needle insertion at upper end of plication due to increased intraluminal pressure and its dilation in one point which was treated by simple suture by laparoscopy; and the last one due to fundus sliding outside of suture row and blowout of dilated displaced fundus. Treatment of this case was by laparotomy, undoing the suture line and drain insertion. During follow up it took about 2 weeks for fistula to evolve and closure of fistula completed after 45 days and drains were taken out afterwards.

Intrahepatic hematoma due to fan retractor manipulation predisposed intracapsular liver abscess formation after 6 months in one case. The hematomas did not occur again due to using the new question mark liver retractor.

Postoperative obstruction presented by continuous vomiting was seen in three cases due to displacement of released fundus outside the suture line and extra-expansion. But instead of dilation at needle insertion point or blowout, the displaced folds stretched the string, tightening the rest of the knots especially the last one near pylorus. The stomach outflow kinked and produced an obstruction. The management was via laparoscopy. The suture line was undone and replication performed. The last tie close to the pylorus was done relatively looser than before.

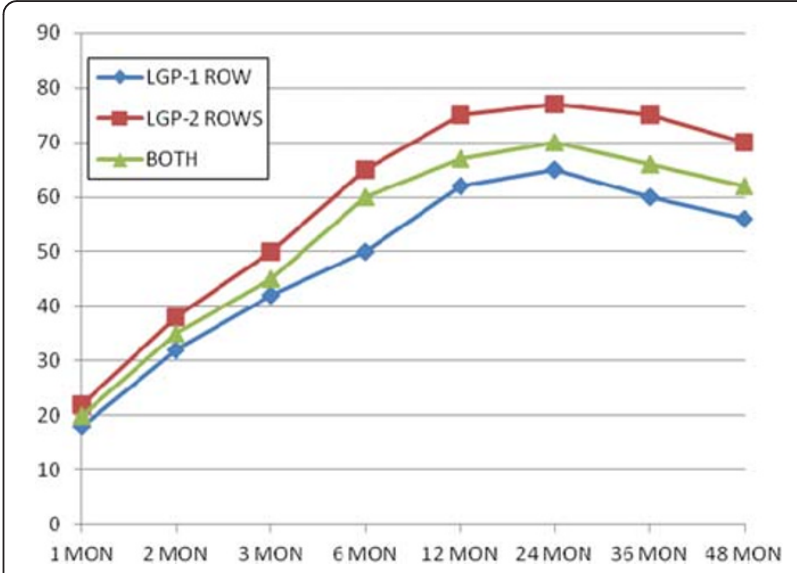

Figure 8 Comparing Excess Weight Loss between one- and two-row LGP. 

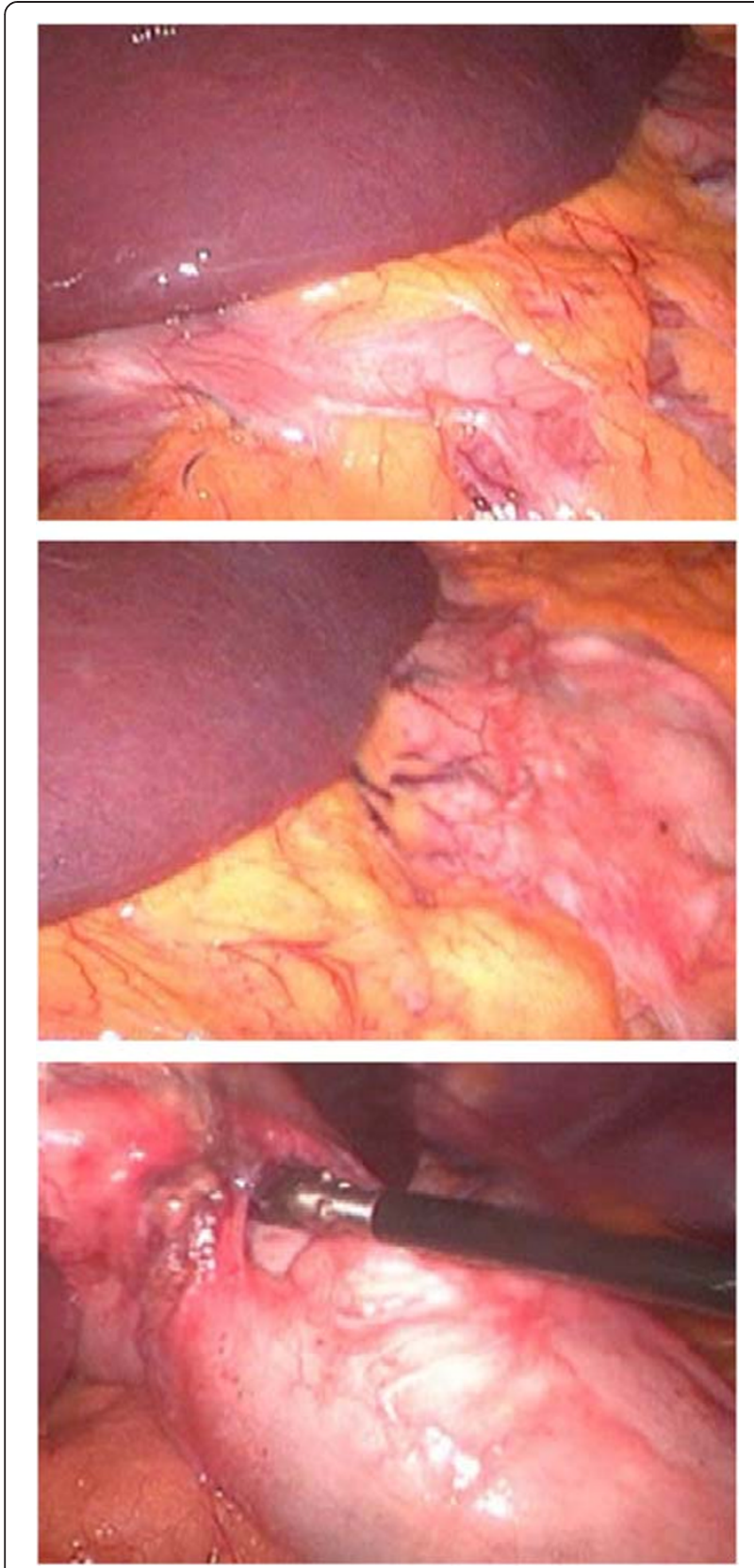

Figure 9 Plicated stomach after 3 years.
In another case due to unusual adhesion between fundus and traumatized liver, permanent vomiting and discomfort was seen. Actually in this case laparoscopic reoperation 8 months later resolved the problem. In this surgery the adhesion was released and plication was undone.

Undoing of LGP in first case by cut of thread and separation of folds performed with limited adhesions. In second one adhesion between folds was really strong and separation was hard (Table 5).

156 and 644 cases underwent one- and two-row plication respectively. All of complications were seen in former technique except two obstruction cases in the latter (0.3\%). Comparing EWL showed it was the same at first but higher at long term due to less anatomic volume and prominent functional restrictive effect in two-row technique. $(50 \%$ and $65 \%$ after 6 months, $62 \%$ and $75 \%$ after 12 months, $65 \%$ and $77 \%$ after 2 years, $60 \%$ and $75 \%$ after 3 years and $56 \%$ and $70 \%$ after 4 years in one- and two-row respectively) (Figure 8).

Reoperation due to regain (32), failure (6) or other reasons (gallstone 12, appendicitis 3) was done in 53 cases and plication rechecked. These cases showed unchanged suture line but little expansion of the stomach (Figure 9). Fibrotic bands around plication had reinforced it. In 25 out of 38 cases of regain or failure, outside displacement of plicated fold was seen (65\%).

The rate of late (after 1 month of operation) postoperative complication was zero. Some comorbidities was present before surgery in $18 \%$ of cases including $11 \%$ diabetes, $5 \%$ knee or low back pain, $4 \%$ hypertriglyceridemia, $1 \%$ hypertension, and $0.5 \%$ sleep apnea. Six months and one year after operation, respectively $70 \%$ and $95 \%$ of diabetic cases changed into non diabetics (40\% after 2 months) and the remaining needed to taper their medical therapy; $80 \%$ and $100 \%$ knee or low back pain, $40 \%$ and $70 \%$ of hypertriglyceridemia, $50 \%$ and $80 \%$ of hypertension and all of sleep apnea cases recovered from diseases. 2 cases out of 55 regain patients complained of diabetes again (Table 6).

The mean time of operation was 72 (49-152) minutes; all were discharged after an average time of 72 hours

Table 6 Comorbidities in LGP cases and the recovery percentage

\begin{tabular}{lccc}
\hline \multicolumn{1}{c}{ COMORBIDITY } & Frequency & \% OF RECOVERY AFTER 6 MON & \% OF RECOVERY AFTER 1 YEAR \\
\hline DIABET & $11 \%$ & $70 \%$ & $95 \%$ \\
HYPERTENSION & $1 \%$ & $50 \%$ & $80 \%$ \\
KNEE OR LOW BACK PAIN & $5 \%$ & $80 \%$ & $100 \%$ \\
HYPERTRIGLYCERIDEMIA & $4 \%$ & $40 \%$ & $70 \%$ \\
SLEEP APNEA & $0.5 \%$ & $100 \%$ & $100 \%$ \\
TOTAL & $18 \%$ & $35 \%$ & $67 \%$ \\
\hline
\end{tabular}


Table 7 Regain or failure after up to 8 years of effective period of LGP (4 years)

\begin{tabular}{llll}
\hline REGAIN & NUMBER & NEW PLAN & OUTCOME \\
\hline WRONG SELECTION & 31 regain & MALABSORPTIVE & 20 CASES, \\
TEMPORARY NEW CONDITION & 6 failure & & $78 \%$ EWL/ 1 YEAR \\
& 13 & 11 REPLICATION & 11 CASES LGP, \\
PERMANENT NEW CONDITION & & 2 GASTRIC BYPASS & $55 \%$ EWL/ 2 YEAR \\
TOTAL & 5 & MALABSORPTIVE & 5 CASES \\
& $55 / 176(31 \%)$ & $68 \%$ MAL, & 38 CASES, \\
\hline
\end{tabular}

(24 hours to 45 days). It was 100 minutes when dissection of greater curvature was done by coagulation and suture and 67 minutes when it was done by LigaSure ${ }^{\mathrm{TM}}$ or Ultracision.

\section{Regain and failure}

In experience there was about $31 \%$ regain after up to 8 years of effective time (4 year period) of operation (55 out of 176), which was $5.5 \%$ up to 4 years after operation (26 out of 490 ) and $42 \%$ after 10 years (15 out of 35 ). Cases with less than 30\% EWL after 4 years were included in regain group. We put 6 failure cases with less than 30\% EWL during first 6 months in it as well.

The main regain and failure group was cases with wrong selection of technique, mainly males without good motivation and co-working (31 regain and 6 failure cases). The plan for this group was malabsorptive operation that has done in 20 cases with excellent EWL (78\% EWL after 1 year). The second group was cases with good result secondary to plication, but due to new conditions (like marriage, pregnancy and psychological disease secondary to familial problems like divorce, death of relatives and so on) lifestyle of patient has changed again. Patients with temporary change of conditions like pregnancy can be managed by replication or gastric bypass. But if the new condition was permanent, the method of choice was malabsorptive. In 11 out of 18 such cases we did replication, gastric bypass in 2 and malabsorptive in 5. The mean EWL after 6 months of replication in these cases was $44 \%$ and after 1 year it was $51 \%$ with mean follow up time of 24 months (55\%) (Table 7).

\section{Discussion}

LGP as a new restrictive method for treatment of morbid obesity has shown acceptable results during its evolution since 12 years ago. The complications were not more than other methods; and costs were far less than any other bariatric surgery. The final result of weight loss was almost the same as other restrictive techniques [29]. However, the wide range of weight loss resulted from different methods of restrictive bariatric surgery means the main reason of weight loss is not just a specific technique; but also could be mostly the patient's motivation to keep appropriate lifestyle $[11,30]$.

\section{Evolution of technique}

Four plans of restrictive method were studied in animal lab (Figure 10). The final version was taken as safest and most effective method to be performed on volunteer cases in year 2000. Three further modifications applied on cases resulted in acceptable one-row plication. But after occurrence of few complications mainly displaced bulging of some plications out of suture line (Figure 11), it had to be more optimized to the two-row plication (Figure 12).

Presentation of early 4 year results of LGP by author [29] increased the interest of famous bariatric surgeons in the world to begin this new bariatric method with acceptable same results [31-33].

Outcome of plicated stomach is well known after about 12 years experience. All technical complications occurred during first week after operation. If the patient could pass first postoperative week without any problem, there was not any risk of complication later on. As the wall of stomach was elastic and intake of food could make extension, increase of intraluminal space occurred gradually. During the first 14 days after operation metabolism of fat and sugar has been probably changed in the liver. The weakness during first 3 weeks was probably due to lack of enough fat and glucose intake and the interval needed for physiologic adaptation in the body to supply glucose by lipolysis in the liver.

The average volume of painless drinking after one-row plication was about $50 \mathrm{cc}$ each time. The main reason was contraction of gastric muscles and also painful peristaltic movement in higher volumes (functional restrictive effect). The volume of stomach in two-row plication was $50 \mathrm{cc}$ (anatomic restriction) but the role of functional restriction in this method was more prominent.

If patient took more than $25 \mathrm{cc}$ each time epigastric pain or esophageal reflux would occur (especially during first 6 months). These were two inhibitory mechanisms preventing 
any change in volume intake. If volume intake was in permitted dose, reflux or pain would not appear.

Functional restriction was due to adhesion of tworow sutures together in which any form of muscular movement could be painful. If two-row sutures get separate, there would be two problems: the inverted fold would be more mobile and risk of removal or displacement and vomiting is higher, and the functional restriction would decrease.

The feeling of postoperative gastric fullness was the possible reason for nausea in all cases, which would be corrected after adaptation.

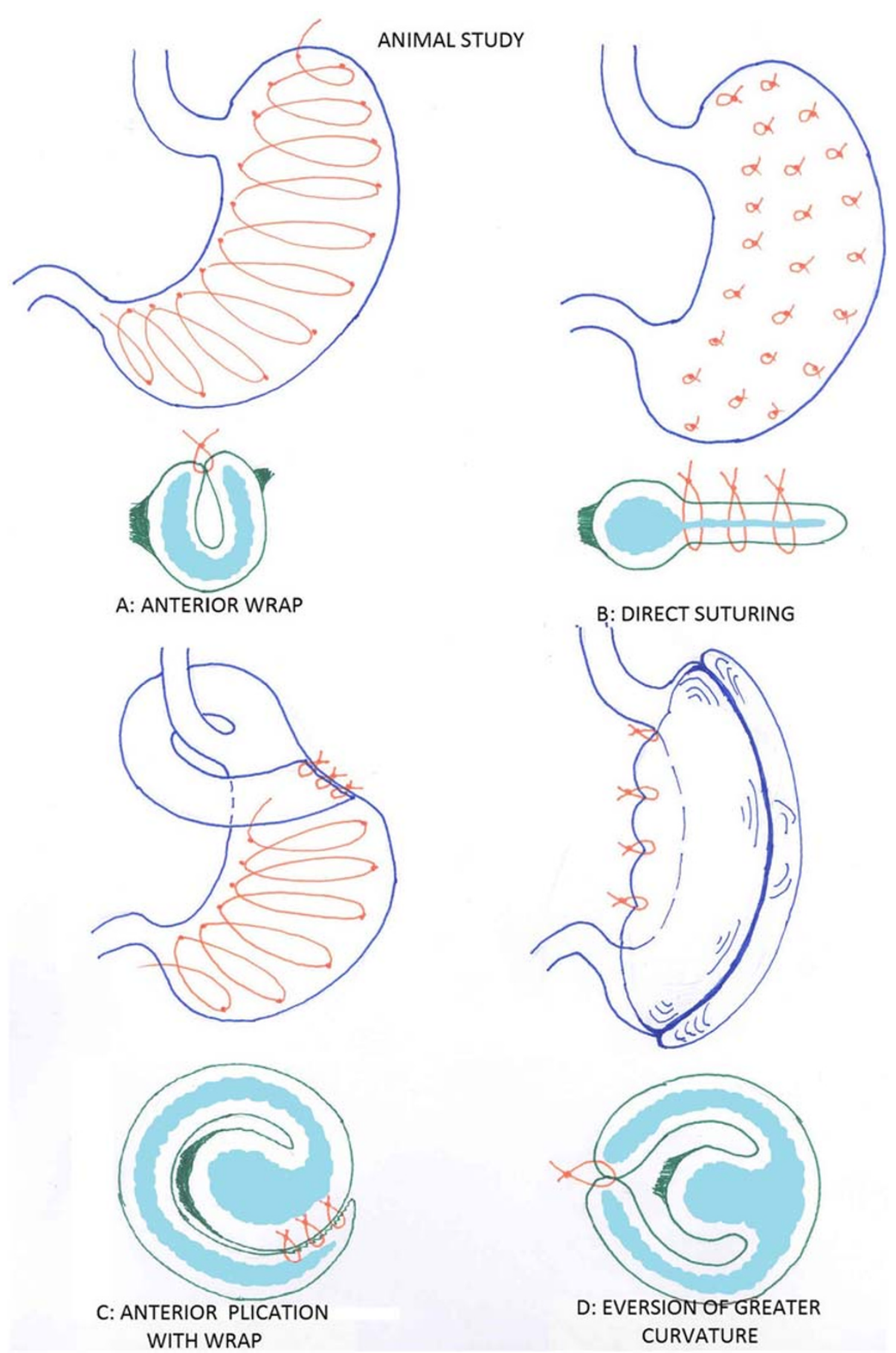

Figure 10 Four plans of restrictive method in animal study. 

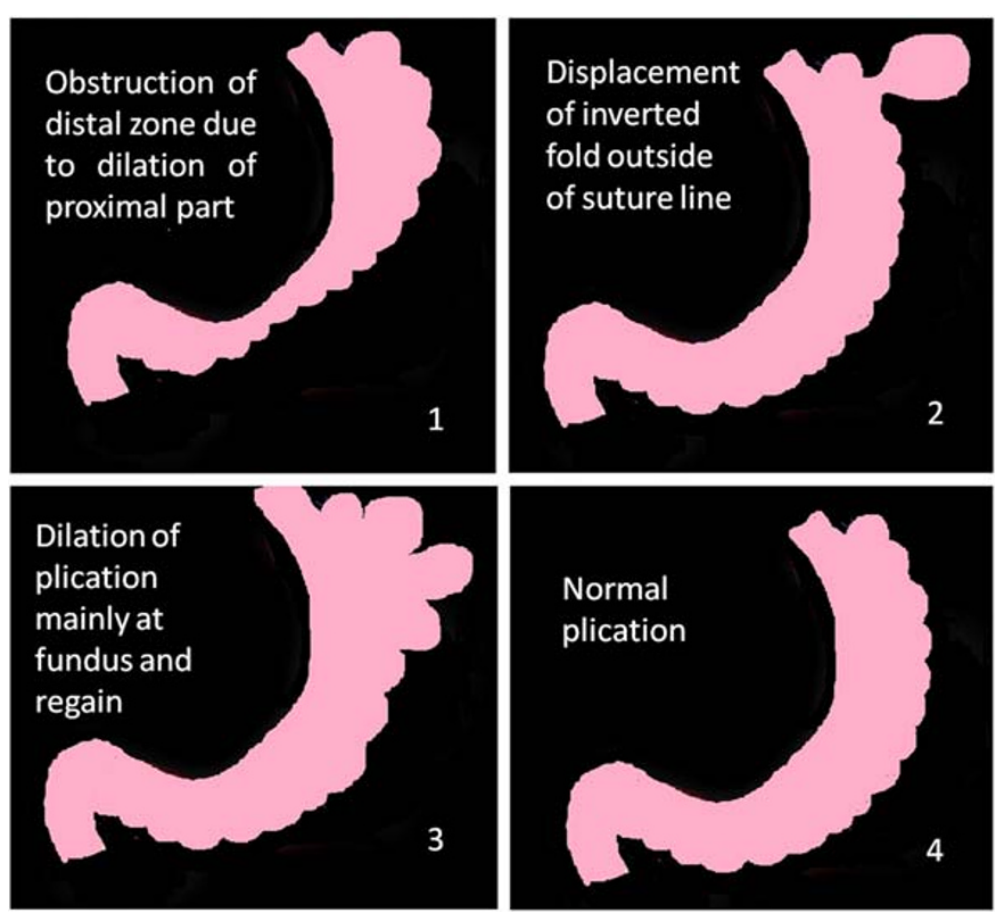

Figure 11 Complication of one row plication.

Temporary postop reflux without any preop history was probably due to high intraluminal pressure and mucosal edema caused by plication. This was observed especially in cases with incompetent lower esophageal sphincter which is seen commonly in morbid obesity. The rate of reflux dropped down due to subsidence of edema after one week.

As the length of string was fixed and the process of gastric extension was gradual, it showed by endoscopy that the string was routinely transposed into the lumen of stomach and removed from the body by defecation after 4 years of operation. Based on endoscopy and mucosal biopsy and chyme analysis in randomized cases and according to reoperation (due to gallstone or appendicitis) findings for regain, plicated fold showed shrinkage due to muscular atrophy, but the mucosa and its circulation was normal because it was in contact to food; so that, its enzymatic, hormonal and mucosal secretion was normal. Shrinkage of plicated fold and extension of elastic gastric wall were two main factors for limited effective time of plication (4 years).

Probability of regain after about 4 years of gastric plication is a fact. If we select the patients correctly and they successfully change their lifestyle, after effective time of operation ( 4 years), they could have a good new condition (normal weight, acceptable psychological mood, new lifestyle) that can prohibit any form of regain. The rate of $42 \%$ regain after 10 years in first 35 cases of LGP was due to learning curve (increase in surgical expertise), one-row method, far away bites from lesser curvature. It needs more cases and more time especially in two-row LGP cases to assess meaningful long term result.

Replication was easier than plication, because release of greater curvature had been done before, adhesions of liver or omentum to stomach were loose and re-suturing over dilated plicated stomach was something like the second row suturing in plication method.

Long term results depend mainly on the extent of motivation to keep on corrected lifestyle. Restrictive effect of surgery takes until 4 years and then enlargement of stomach up to $250 \mathrm{cc}$ is enough to induce regain. But in experience $5.5 \%$ of cases got regain during first 4 years (effective period) and $31 \%$ up to 8 years after effective period of LGP (12 years) and the remaining cases preserve their new lifestyle for long term period. Unfortunately it is not for all life and the percentage rate of regain increased gradually. As the main group of cases were young females and they were interested in plication due to very low complication rate, we think the main factor for increasing motivation of these patients was social factors like marriage; so that after one decade of operation these social factors have been solved and patients' motivations has decreased. Consideration of morbid obesity as a disease and trying to control it was not sufficient motivation for them.

\section{The advantages of LGP}

As the effects of all restrictive methods are almost the same, the best method is the one with the least risk of 
complication. Gastric plication has the least rate of reoperation which is due to $1 \%$ technical (in the first week) and less than $0.2 \%$ late complications. It is noteworthy in comparison to other restrictive methods like gastric banding or sleeve gastrectomy. There is about $10 \%$ to $20 \%$ of emergency band removal (happening in wide range of time after surgery) in gastric banding operation because of balloon leakage, band erosion/migration, deep infection and reaction to foreign body [34]. Reoperation to remove balloon is the most important disadvantage of this technique [27,35-38]. In vertical banded gastroplasty (VBG) the risk of reflux, leak, blow out of stomach, regain and foreign body reaction would be highly observed [30]. Complications secondary to sleeve gastrectomy including leakage, disruption and malabsorption is about $10 \%[36,37,39,40]$. Effective time of all restrictive methods is limited to 3 to 4 years, so risk of regain is the problem of all kinds of bariatric surgeries.

Especial hormones of stomach (Ghrelin, Leptin etc.) make an appetite balance in normal condition. Although the effect of ghrelin on appetite is remarkable, balance between gastric hormones and appetite was not changed after sleeve gastrectomy [13-17]. Losing appetite is related to decreased intraluminal space and high intraluminal pressure. This mechanism is more noticeable in gastric plication. When intraluminal space increases during time, appetite increases as well regardless of surgical technique used.

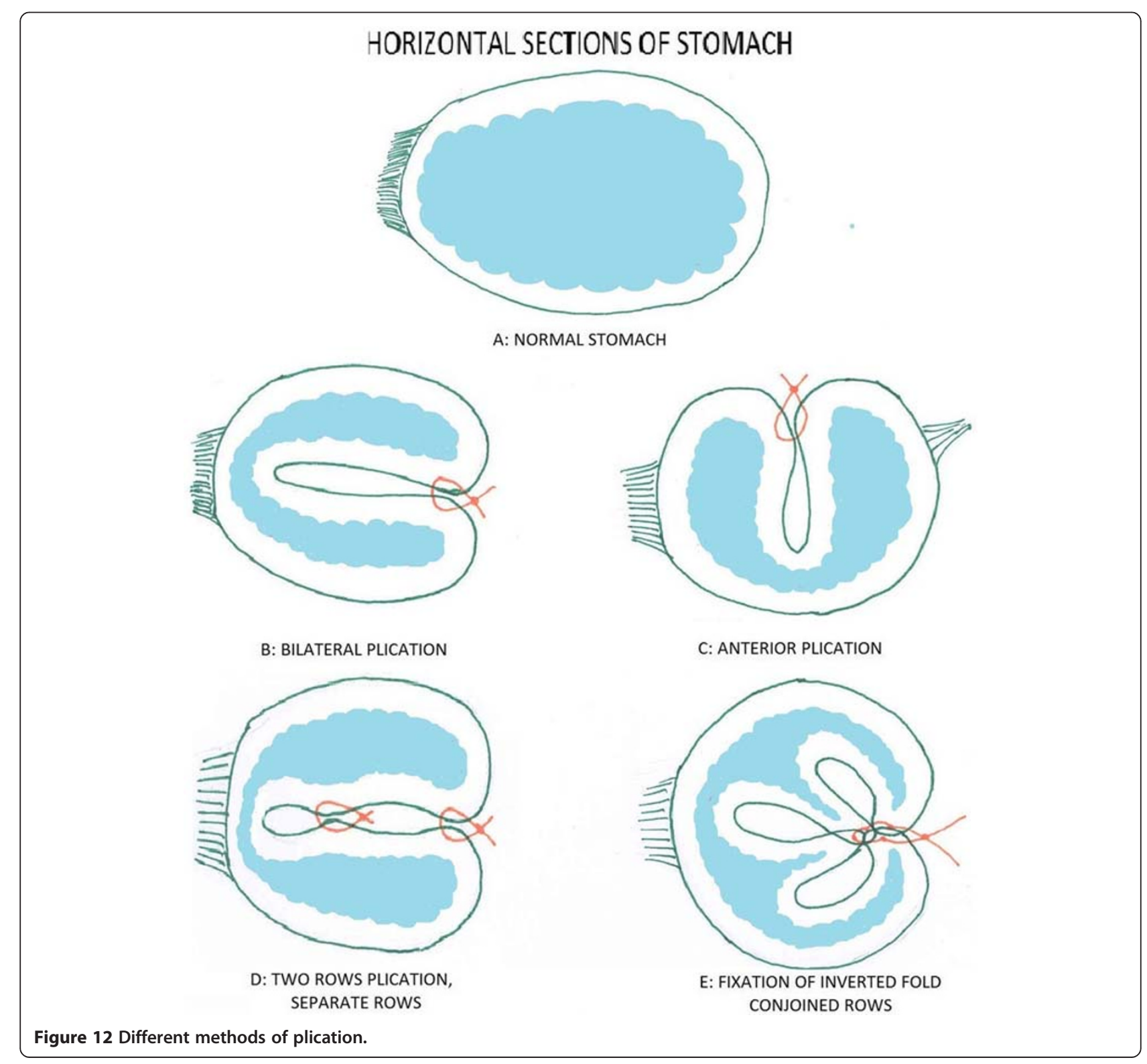


Table 8 Advantages of LGP

\begin{tabular}{lc}
\hline ADVANTAGES & DETAIL \\
\hline LACK OF FOREIGN BODY & PROLEN \\
LOW MORBIDITY & VOMITING \\
COST EFFECTIVE & ANY STAPLER \\
LOW COMPLICATION & $1 \%$ \\
INDIPENDENT & PSYCHOLOGICALLY \\
REVERSIBLE & CUT OF THREAD \\
LACK OF APPETITE & LACK OF SPACE \\
FUNCTIONAL RESTRICTIVE EFFECT & PAINFUL PERISTALTISM \\
\hline
\end{tabular}

To sum it up, advantages of LGP over other restrictive methods are as follows. First, the patient is independent postoperatively with easy follow up; which means the patient is free from any obligatory post-operative procedures e.g. balloon size regulation in gastric banding. No foreign body reaction is the next advantage of LGP as only two or three prolen or nylon threads are used with no use of mesh or band. Moreover, less cost due to no need for stapler or band and short period of postoperative hospitalization are very important factors for patients. Less complication such as leakage, infection or erosion should be noted since this method is the most conservative procedure among other bariatric surgeries with no resection or anastomosis.

Psychological situation in these patients is satisfying since they are independent to surgeon after the surgery and have no fear of any complications of foreign bodies. It is interesting that 4 years after gastric plication patients will have no sign of surgery in their stomach, the string will pass through GI tract, muscular layer of inverted folds will be hypotrophied and actually weight loss will occur without any change or sequel in the body.

If needed, this method is reversible during first 6 weeks just by cutting the suture lines and easily releasing the mild adhesions. Reversion of LGP later is difficult and it needs tense fibrotic tissue dissection. It can be followed by adding malabsorptive method as a second stage operation in cases with insufficient weight loss without any change to previous surgery. EWL in this technique is the same as other restrictive surgeries (Table 8).

Comparing this technique with using stapler and resection of greater curvature, LGP is less invasive and more conservative with reversible potency and less risk of complications such as leakage.

Making both wrap and plication to decrease the volume of stomach predisposes higher risk of suture pressure and possibility of leakage. Anterior plication without release of greater curvature is less invasive but has more risk for weight regain.

If patient is poorly cooperative and less likely to change lifestyle in the future, restrictive operation is not a good option and patient needs malabsorptive bariatric surgery. Although risk of morbidity and mortality in malabsorptive methods are higher than restrictive, this is a good choice in this group [14,41-43].

In duodenal switch (DS) there is a significant malabsorptive component, so the patient must be closely monitored for nutritional deficiencies. These patients are at greater risk of chronic diarrhea, more foul smelling stools and flatus. In gastric bypass because it includes resection, anastomosis and malabsorption, the risk of mortality and morbidity are $1 \%$ and up to $15 \%$ respectively [44].

Although the risk of mortality and morbidity in bariatric surgery is high (less than $1 \%$ mortality and $10 \%$ morbidity), most patients accept the risk because of their miserable and limited life secondary to morbid obesity.

A special diet after restrictive operation with high speed weight loss has made the question about composition of lost tissue [45]. Is all of it fatty tissue? Or water and protein has lost secondary to this form of high speed weight loss.

The mechanism of high catabolism of fatty tissue after operation in comparison to traditional diet is not well known but enzymatic and hormonal change in the body could be the main factor. More study in this field can be helpful to find new strategies for treatment of morbid obesity in the future.

\section{Conclusion}

Laparoscopic gastric plication is as effective as other restrictive methods to lose weight. Its advantages include: easy follow up, no foreign body, much less cost, low complications $(0.6 \%)$, low reoperation (1\%), only $31 \%$ regain up to 12 years follow up, easy plan for regain group, psychological advantage due to independency to surgeon and sense of normal physiology and anatomy without any resection. This method is reversible if needed and also does not prohibit complementary malabsorptive methods (2 stage operation) in cases with insufficient weight loss.

\section{Abbreviations \\ RM: Restrictive method; LGP: Laparoscopic gastric plication; EWL: Excess weight loss; RGEA: Right gastroepiploic artery; NGT: Nasogastric tube.}

\section{Competing interests}

The authors declare that they have no competing interest.

\section{Authors' contributions}

MT has evolved the surgical technique and participated in conception and design of study. He was responsible for obtaining funding for study and final approval. SMKM was responsible for critical revision of study manuscript and participated in scientific writing. AT participated in provision of study material and collection and assembly of raw data. HV was responsible for analysis and interpretation of data, participated in collection of data and writing the manuscript draft. He is corresponding to letter. All authors declare that they have read and accepted the final manuscript to be submitted. 


\section{Authors' information}

Mohammad Talebpour got his general surgery degree from Tehran University of Medical Sciences (TUMS). His subspecialty is advanced laparoscopy from Ninewells Hospital, UK. He is associate prof of TUMS, Head of laparoscopic ward, Sina Hospital, Tehran, Iran.

SMKM is an MD/MPH graduate from Tehran University of Medical Sciences (TUMS). He has been involved in endocrinological research and related fields since 2009 in Endocrinology and Metabolism Research Center (EMRC) in Iran. He has been recently started cooperation with Laparoscopic Surgery Ward of Sina Hospital. Atieh Talebpour is an MD graduate from Tehran University of Medical Sciences (TUMS). She has been involved in surgical research in Laparoscopic Surgery Ward of Sina Hospital.

Hamed Vahidi is an MD/MPH graduate from Tehran University of Medical Sciences (TUMS). He has been involved in surgical research in Laparoscopic Surgery Ward of Sina Hospital. He is the second student of general examination of medical science in Iran. His research experience was with Endocrinology and Metabolism Research Center (EMRC) and Pharmacologic Research Center in Iran.

\section{Acknowledgements}

We acknowledge the sincere cooperation of all surgical and clinical staff at Laleh and Sina Hospitals. We would also like to thank Dr. Hamed Noorani for his contribution to producing brilliant and scientific pictures. We finally wish to express our gratitude to Dr Mohammad Hossein Kalantar Motamedi for his invaluable technical comments and language edit.

Received: 30 August 2011 Accepted: 15 August 2012

Published: 22 August 2012

\section{References}

1. Drewnowski A, Popkin BM: The nutrition transition: new trends in the global diet. Nutr Rev 1997, 55:31-43.

2. Popkin BM: The Nutrition Transition: An Overview of World Patterns of Change. Nutr Rev 2004, 62(7 Pt 2):S140-S143.

3. Posner BM, Franz MM, Quatromoni PA, Gagnon DR, Sytkowski PA, D'AGOSTINO RB, Cupples LA: Secular Trends in Diet and Risk Factors for Cardiovascular Disease: The Framingham Study. J Am Diet Assoc 1995, 95:171-179.

4. Popkin BM: The nutrition transition: an overview of world patterns of change. Nutr Rev 2004, 62:S140-S143.

5. Finucane MM, Stevens GA, Cowan MJ, Danaei G, Lin JK, Paciorek CJ, Singh GM, Gutierrez HR, Lu Y, Bahalim AN: National, regional, and global trends in body-mass index since 1980: systematic analysis of health examination surveys and epidemiological studies with 960 country-years and 9. 1 million participants. Lancet 2011, 12; 377(9765):557-67.

6. Ruesten A, Steffen A, Floegel A, DL A, Masala G, Tjonneland A, Halkjaer J, Palli D, Wareham NJ, Loos RJ, et al: Trend in obesity prevalence in European adult cohort populations during follow-up since 1996 and their predictions to 2015. PLoS One 2011, 6:e27455.

7. Basterra-Gortari FJ, Beunza JJ, Bes-Rastrollo M, Toledo E, Garcia-Lopez M, Martinez-Gonzalez MA: [Increasing trend in the prevalence of morbid obesity in Spain: from 1.8 to 6.1 per thousand in 14 years]. Rev Esp Cardiol 2011, 64:424-426.

8. Komlos J, Brabec M: The trend of mean BMI values of US adults, birth cohorts 1882-1986 indicates that the obesity epidemic began earlier than hitherto thought. Am J Hum Biol 2010, 22:631-638.

9. Flegal KM, Carroll MD, Ogden CL, Curtin LR: Prevalence and trends in obesity among US adults. JAMA 1999-2008, 303:235-241.

10. Himpens J, Cadiere GB, Bazi M, Vouche M, Cadiere B, Dapri G: Long-term Outcomes of Laparoscopic Adjustable Gastric Banding. Arch Surg 2011, 146(7):802-807.

11. Deveney CW, Martindale RG: Factors in selecting the optimal bariatric procedure for a specific patient and parameters by which to measure appropriate response to surgery. Curr Gastroenterol Rep 2010, 12:296-303.

12. Farrell TM, Haggerty SP, Overby DW, Kohn GP, Richardson WS, Fanelli RD: Clinical application of laparoscopic bariatric surgery: an evidence-based review. Surg Endosc 2009, 23:930-949.

13. Brody F: Minimally invasive surgery for morbid obesity. Cleve Clin J Med 2004, 71:289-293. 296-288.

14. Garb J, Welch G, Zagarins S, Kuhn J, Romanelli J: Bariatric surgery for the treatment of morbid obesity: a meta-analysis of weight loss outcomes for laparoscopic adjustable gastric banding and laparoscopic gastric bypass. Obes Surg 2009, 19:1447-1455.

15. Sasse KC, Ganser JH, Kozar MD, Watson RW 2nd, Lim DC, McGinley L, Smith CJ, Bovee V, Beh J: Outpatient weight loss surgery: initiating a gastric bypass and gastric banding ambulatory weight loss surgery center. JSLS 2009, 13:50-55.

16. Kim TH, Daud A, Ude AO, DiGiorgi M, Olivero-Rivera L, Schrope B, Davis D, Inabnet WB, Bessler M: Early U.S. outcomes of laparoscopic gastric bypass versus laparoscopic adjustable silicone gastric banding for morbid obesity. Surg Endosc 2006, 20:202-209.

17. Langer FB, Reza Hoda MA, Bohdjalian A, Felberbauer FX, Zacherl J, Wenzl E, Schindler K, Luger A, Ludvik B, Prager G: Sleeve gastrectomy and gastric banding: effects on plasma ghrelin levels. Obes Surg 2005, 15:1024-1029.

18. Doherty C, Maher JW, Heitshusen DS: Long-term data indicate a progressive loss in efficacy of adjustable silicone gastric banding for the surgical treatment of morbid obesity. Surgery 2002, 132:724-727. discussion 727-728.

19. Jacobs PP, van Uchelen FA C, Bruyninckx CM, Donker FJ, Driessen WM, Breuer C: [Medium-long-term good results of vertical gastroplasty in the treatment of morbid obesity]. Ned Tijdschr Geneeskd 1991, 135:1445-1449.

20. Crea N, Pata G, Di Betta E, Greco F, Casella C, Vilardi A, Mittempergher F: Long-term results of biliopancreatic diversion with or without gastric preservation for morbid obesity. Obes Surg 2011, 21:139-145.

21. Ocon Breton J, Perez Naranjo S, Gimeno Laborda S, Benito Ruesca P, Garcia Hernandez R: [Effectiveness and complications of bariatric surgery in the treatment of morbid obesity]. Nutr Hosp 2005, 20:409-414.

22. Doherty C, Maher JW, Heitshusen DS: Prospective investigation of complications, reoperations, and sustained weight loss with an adjustable gastric banding device for treatment of morbid obesity. J Gastrointest Surg 1998, 2:102-108.

23. Juhasz-Pocsine K, Rudnicki SA, Archer RL, Harik SI: Neurologic complications of gastric bypass surgery for morbid obesity. Neurology 2007, 68:1843-1850.

24. Cariani S, Nottola D, Grani S, Vittimberga G, Lucchi A, Amenta E: Complications after Gastroplasty and Gastric Bypass as a Primary Operation and as a Reoperation. Obes Surg 2001, 11:487-490.

25. Chevallier J-M, Zinzindohoué F, Douard R, Blanche J-P, Berta J-L, Altman J-J, Cugnenc P-H: Complications after Laparoscopic Adjustable Gastric Banding for Morbid Obesity: Experience with 1,000 Patients over 7 Years. Obes Surg 2004, 14:407-414.

26. Franco JV, Ruiz PA, Palermo M, Gagner M: A Review of Studies Comparing Three Laparoscopic Procedures in Bariatric Surgery: Sleeve Gastrectomy, Roux-en-Y Gastric Bypass and Adjustable Gastric Banding. Obes Surg 2011, 21(9):1458-1468.

27. Birkmeyer NJ, Dimick JB, Share D, Hawasli A, English WJ, Genaw J, Finks JF, Carlin AM, Birkmeyer JD: Hospital complication rates with bariatric surgery in Michigan. JAMA 2010, 304:435-442.

28. Campbell J, McGarry LA, Shikora SA, Hale BC, Lee JT, Weinstein MC: Costeffectiveness of laparoscopic gastric banding and bypass for morbid obesity. Am J Manag Care 2010, 16:e174-e187.

29. Talebpour M, Amoli BS: Laparoscopic total gastric vertical plication in morbid obesity. Journal of laparoendoscopic \& advanced surgical techniques Part A 2007, 17:793-798.

30. Scozzari G, Toppino M, Famiglietti F, Bonnet G, Morino M: 10-year followup of laparoscopic vertical banded gastroplasty: good results in selected patients. Ann Surg 2010, 252:831-839.

31. Ramos A, Galvao Neto M, Galvao M, Evangelista LF, Campos JM, Ferraz A: Laparoscopic greater curvature plication: initial results of an alternative restrictive bariatric procedure. Obes Surg 2010, 20:913-918.

32. Pujol Gebelli J, Garcia Ruiz de Gordejuela A, Casajoana Badia A, Secanella Medayo L, Vicens Morton A, Masdevall Noguera C: Laparoscopic Gastric Plication: a new surgery for the treatment of morbid obesity. Cir Esp 2011, 89(6):356-361.

33. Brethauer SA, Harris JL, Kroh M, Schauer PR: Laparoscopic gastric plication for treatment of severe obesity. Surg Obes Relat Dis 2011, 7:15-22.

34. Muller MK, Wenger C, Schiesser M, Clavien PA, Weber M: Quality of life after bariatric surgery--a comparative study of laparoscopic banding vs. bypass. Obes Surg 2008, 18:1551-1557.

35. Campos GM, Rabl C, Roll GR, Peeva S, Prado K, Smith J, Vittinghoff E: Better weight loss, resolution of diabetes, and quality of life for laparoscopic 
gastric bypass vs banding: results of a 2-cohort pair-matched study. Arch Surg 2011, 146:149-155.

36. Abbatini F, Rizzello M, Casella G, Alessandri G, Capoccia D, Leonetti F, Basso $\mathrm{N}$ : Long-term effects of laparoscopic sleeve gastrectomy, gastric bypass, and adjustable gastric banding on type 2 diabetes. Surg Endosc 2010, 24:1005-1010.

37. Boza C, Gamboa C, Awruch D, Perez G, Escalona A, Ibanez L: Laparoscopic Roux-en-Y gastric bypass versus laparoscopic adjustable gastric banding: five years of follow-up. Surg Obes Relat Dis 2010, 6:470-475.

38. Gutschow CA, Collet P, Prenzel K, Holscher AH, Schneider PM: Long-term results and gastroesophageal reflux in a series of laparoscopic adjustable gastric banding. J Gastrointest Surg 2005, 9:941-948.

39. D'Hondt M, Vanneste S, Pottel H, Devriendt D, Van Rooy F, Vansteenkiste F: Laparoscopic sleeve gastrectomy as a single-stage procedure for the treatment of morbid obesity and the resulting quality of life, resolution of comorbidities, food tolerance, and 6-year weight loss. Surg Endosc 2011, 25(8):2498-2504.

40. Omana JJ, Nguyen SQ, Herron D, Kini S: Comparison of comorbidity resolution and improvement between laparoscopic sleeve gastrectomy and laparoscopic adjustable gastric banding. Surg Endosc 2010, 24:2513-2517.

41. Mognol P, Chosidow D, Marmuse JP: Laparoscopic gastric bypass versus laparoscopic adjustable gastric banding in the super-obese: a comparative study of 290 patients. Obes Surg 2005, 15:76-81.

42. Simpfendorfer $\mathrm{CH}$, Szomstein S, Rosenthal R: Laparoscopic gastric bypass for refractory morbid obesity. Surg Clin North Am 2005, 85:119-127. x.

43. Ballantyne GH, Wasielewski A, Saunders JK: The surgical treatment of type II diabetes mellitus: changes in HOMA Insulin resistance in the first year following laparoscopic Roux-en-Y gastric bypass (LRYGB) and laparoscopic adjustable gastric banding (LAGB). Obes Surg 2009, 19:1297-1303.

44. Pontiroli $A E$, Morabito A: Long-term prevention of mortality in morbid obesity through bariatric surgery. a systematic review and meta-analysis of trials performed with gastric banding and gastric bypass. Ann Surg 2011, 253:484-487.

45. Strain GW, Gagner M, Pomp A, Dakin G, Inabnet WB, Hsieh J, Heacock L, Christos P: Comparison of weight loss and body composition changes with four surgical procedures. Surg Obes Relat Dis 2009, 5:582-587.

doi:10.1186/1750-1164-6-7

Cite this article as: Talebpour et al.: Twelve year experience of laparoscopic gastric plication in morbid obesity: development of the technique and patient outcomes. Annals of Surgical Innovation and Research 2012 6:7.

\section{Submit your next manuscript to BioMed Central and take full advantage of:}

- Convenient online submission

- Thorough peer review

- No space constraints or color figure charges

- Immediate publication on acceptance

- Inclusion in PubMed, CAS, Scopus and Google Scholar

- Research which is freely available for redistribution 